\title{
Study of Sterility Mosaic Disease Resistance on Immortal Population in Pigeonpea
}

\author{
Shourabh Joshi ${ }^{1 *}$, T. Revathi ${ }^{1}$, G. Umadevi ${ }^{1}$, C.V. Sameer Kumar ${ }^{2}$ and G. Anuradha ${ }^{3}$ \\ ${ }^{1}$ Institute of Biotechnology, College of Agriculture, Rajendranagar-Hyderabad, Telangana, India \\ ${ }^{2}$ International Crops Research Institute for the Semi-Arid Tropics, Telangana, India \\ ${ }^{3}$ Regional Agricultural Research Station, Palem, Telangana, India \\ *Corresponding author
}

\begin{tabular}{|c|c|}
\hline & A B S T RA C T \\
\hline & \multirow{6}{*}{$\begin{array}{l}\text { The cultivated pigeon pea (Cajanus cajan) is one of the most important source of protein } \\
\text { for worlds marginal and vegetarian population. Sterility mosaic disease (SMD) also known } \\
\text { as "green plague of pigeonpea" is one of the severe threats in pigeon pea production } \\
\text { causing severe yield loss. Keeping this in view, identification of SMD resistant cultivars } \\
\text { with better understanding of inheritance of disease were key consideration for the present } \\
\text { study. RILs were screened for SMD resistance with leaf stapling technique at Green house, } \\
\text { IBT, PJTSAU during Kharif } 2012 \text { and } 2013 \text {. RILs showed digenic ratio (9S:7R) for SMD } \\
\text { resistance, indicating complementary gene action which showed dominance of } \\
\text { susceptibility over resistant and based on the per cent disease incidence, the RILs could be } \\
\text { broadly classified as resistant (PDI <20\%) and susceptible (PDI >20\%). The SMD } \\
\text { incidence among the } 188 \text { RILs ranged from } 0 \text { to } 100 \% \text { whereas, the susceptible parent } \\
\text { (ICP } 8863 \text { ) showed mean value of } 79.17 \% \text { and resistant parent (ICPL 20097) showed it as } \\
\text { 0\%. Out of total } 188 \text { RILs screened, } 90 \text { RILs showed resistant reaction to SMD infection } \\
\text { while } 98 \text { RILs were susceptible. } 33 \text { RILs were identified as resistant lines which } \\
\text { consistently showed 0\% PDI during screening for both the years. }\end{array}$} \\
\hline & \\
\hline $\begin{array}{l}\text { RIL, SMD, DAS, } \\
\text { Complementary } \\
\text { gene action. }\end{array}$ & \\
\hline Article Info & \\
\hline $\begin{array}{l}\text { Accepted: } \\
\text { 14 July } 2017 \\
\text { Available Online: } \\
\text { 10 September } 2017\end{array}$ & \\
\hline & \\
\hline
\end{tabular}

\section{Introduction}

Pulses are legumes and rich source of protein to most of the world's marginal and vegetarian population. It helps to supplement dietary requirements, improve nutritional quality, food security and environmental sustainability. Pigeonpea can be attacked by more than 100 pathogens i.e. sterility mosaic disease, fusarium wilt, phytophthora blight, macrophomina root rot, stem canker, and alternaria blight are economically important diseases. Among them sterlity mosaic (SM) is the most viable disease in India and considered as the 'green plague of pigeonpea'. SMD is caused by PPSMV and it is transmitted by an eriophyid mite, Aceria cajani. There are five major isolates which causes SMD, among them Patancheru, Bangalore and Coimbatore isolates are well studied.

\section{Material and Methods}

Two parental lines viz., ICPL 20097 and ICP 8863 with contrasting SMD resistance were selected for development of mapping populations and 188 RIL population were 
developed by Saxena et al., (2010). ICPL 20097 was resistant to SMD while ICP 8863 (Maruti) was susceptible to SMD. ICP 8863 is a high yielding, medium duration variety developed by pure line selection from a land race found in Telangana and Andra Pradesh.

Screening of RILs for SMD was carried out at Greenhouse, Institute of Biotechnology (IBT), Professor Jayshanker Telangana State Agricultural University (PJTSAU), Rajendranagar, Hyderabad. 188 RILs along with their parents were evaluated for resistance to SMD for two consecutive years during the Kharif 2012 and 2013. Parents along with RILs and susceptible check (ICP 8863 after every 10 entries, to monitor the disease spread) were raised in $15 \times 45 \mathrm{~cm}$ polythene bags. In order to ensure better germination, uphold adequate plant stand and protection of growing seedlings from rains, an innovative top covered structure were designed inside the green house itself. Seedlings were protected from rains in order to avoid washing of mites population from the leaf surface.

SMD infected pigeonpea leaves with mite population were collected from SMD infected plants maintained at disease infested plot, ICRISAT, Patancheru. At least two healthy leaflets were stapled with SMD infected leaves at two-leaf stage to transmit the pathogen. As the stapled leaflets of infected plants dry, mites infected with PPSMV migrate from them and transmit the virus to the healthy plants. Leaf stapling was performed 20 days after sowing (DAS).

Plants were scored for incidence of SMD at 15 days interval from day after first inoculation up to 90 days by counting the healthy plants (no mosaic symptoms) and diseased plants (with mosaic symptoms). Based on percent disease incidence population were classified as; resistant (0$10 \%$ PDI), moderately resistant (10.1-20\%
PDI), moderately susceptible (20.1\%-40\% PDI) and susceptible classes (40.1-100\% PDI) (Singh et al., 2003). Disease scoring was done on the basis of percentage of affected plants wherein $0 \%$ means complete resistance while $100 \%$ means complete susceptibility to SMD. Percent disease incidence (PDI) was obtained based on the percentage of infected plants to the total number of plants inoculated in each RIL. PDI was estimated using the following formula.

$\%$ disease incidence perentry $=\frac{\text { Number of diseased plants per entry }}{\text { Total number of plants per entry }} \times 100$

Chi-square $(\chi 2)$ analysis was performed to test the goodness of fit of different Mendelian ratios for SMD by using observed and expected frequencies for SMD obtained based on various classes of disease reaction (resistant and susceptible) in order to understand the number of genes that are involved in governing the disease resistance mechanism.

\section{Results and Discussion}

Sterility mosaic disease (SMD), also known as the "green plague of pigeonpea" and caused by pigeonpea sterility mosaic virus (PPSMV) is one of the major biotic stress in pigenpea, which leads to heavy yield losses and hence posses a big challenge for pigeonpea production in the Indian subcontinent. With an aim of studying SMD resistance, RIL population, i.e. ICPL $20097 \times$ ICP 8863 (segregating for Patancheru SMD isolate) were phenotyped for resistance to SMD. Screening of 188 RILs along with resistant and susceptible parents for SMD was carried out in the green house at IBT, Rajendranagr, PJTSAU during Kharif 2012 and 2013 by leaf stapling technique. Thirty three RILs were identified as consistently resistant lines during both the years and all 33 showed 0 per cent SMD infestation. They were as RIL no. 3, 11, 12, 21, 29, 30, 40, 44, 
$45,53,54,74,89,99,102,107,112,115$, $117,138,142,146,150,152,164,174,176$, 179, 186, 187, 189, 191 and 194. ICPL 20097 ( $<10 \%$ infestation) was found resistant while ICP 8863 was grouped under susceptible category ( $>40 \%$ infestation).

SMD incidence in the susceptible check (ICP 8863 ) ranged from 75.00 to $83.33 \%$ indicating the intense screening for disease resistance taken up in the green house over two cropping seasons of Kharif 2012 and 2013 at IBT, PJTSAU, Rajendranagar, Hyderabad. The SMD incidence among the RILs ranged between 0 to $100 \%$ at individual level and 3.14 to $56.01 \%$ as per respective class with a mean of $25.23 \%$ whereas the parents showed mean value of $79.17 \%$ (ICP 8863) and 0\% (ICPL 20097) for SMD incidence (Table 1). The frequency distribution of SMD incidence for the population is presented in the histograms, which indicate the presence of several genes governing SMD resistance (Fig. 1). The higher number of lines was found to be susceptible among the RILs, indicating the role of different genetic factors contributing to SMD resistance in pigeonpea. SMD incidence were reported high during 2013 screening after using top covered structure since it will protect test plants with the effect of rain.

The observed and expected frequencies obtained from the calculated PDI values were subjected to $\chi 2$ test which showed a goodness of fit to 9 susceptible: 7 resistant at 5\% probability level. The hypothesis for genetic ratio 9:7 is represented in (Table 2). Thus the resistant reaction of the RILs for SMD indicated dominance of susceptibility over resistance. A digenic ratio (9S: 7R) was observed which indicates the complementary nature of two dominant genes for susceptibility to SMD.

Table.1 Summary statistic of Percent Disease Incidence (PDI) for Patancheru SMD isolates using RIL population

\begin{tabular}{|c|c|c|c|c|c|c|}
\hline \multirow{2}{*}{ Class } & \multicolumn{2}{|c|}{$\begin{array}{c}\text { Kharif 2012 } \\
\text { (Green house screening) }\end{array}$} & $\begin{array}{c}\text { Kharif 2013 } \\
\text { (Green house screening) }\end{array}$ & \multicolumn{2}{l|}{ Overall } \\
\cline { 2 - 7 } & $\begin{array}{c}\text { Avg. Disease } \\
\text { incidence \% }\end{array}$ & No. of RILs & $\begin{array}{l}\text { Avg. Disease } \\
\text { incidence \% }\end{array}$ & No. of RILs & $\begin{array}{l}\text { Avg. Disease } \\
\text { incidence \% }\end{array}$ & No. of RILs \\
\hline $\mathbf{0 - 1 0}$ & 0.31 & 56 & 2.22 & 74 & 3.14 & 67 \\
\hline $\mathbf{1 0 . 1 - 2 0}$ & 13.25 & 31 & 17.22 & 17 & 15.11 & 23 \\
\hline $\mathbf{2 0 . 1 - 4 0}$ & 28.68 & 83 & 31.31 & 32 & 29.92 & 51 \\
\hline $\mathbf{4 0 . 1 - 1 0 0}$ & 52.52 & 18 & 65.28 & 65 & 56.27 & 47 \\
\hline ICP 8863 & \multicolumn{2}{|c|}{83.33} & \multicolumn{2}{c|}{75.00} & \multicolumn{2}{c|}{79.17} \\
\hline ICPL 20097 & \multicolumn{2}{|c|}{0.00} & \multicolumn{2}{c|}{0.00} & \multicolumn{2}{c|}{0.00} \\
\hline
\end{tabular}

Table.2 Summary statistic of Chi Square Test performed to understand gene interaction

\begin{tabular}{|c|c|c|c|c|c|c|c|}
\hline Cross involved & Total RILs & \multicolumn{6}{|c|}{ SMD } \\
\hline \multirow{3}{*}{ ICPL 20097 $\times$ ICP 8863 } & \multirow{3}{*}{188} & \multicolumn{2}{|c|}{ Observed } & \multicolumn{2}{|c|}{ Expected } & Ratio & $\chi \mathbf{2}$ \\
\cline { 3 - 8 } & & $\mathrm{R}$ & $\mathrm{S}$ & $\mathrm{R}$ & $\mathrm{S}$ & \multirow{2}{*}{$7: 9$} & $0.7(\mathrm{Cal})$ \\
\cline { 3 - 7 } & & 90 & 98 & 82.25 & 105.75 & & $3.8(\mathrm{Tab})$ \\
\hline
\end{tabular}

Table $\chi^{2}$ values Significant at $5 \%$ level; Resistant and moderately resistance RILs put together and susceptible and moderately susceptible were also grouped together from overall mean 
Photographs depicting the sequence of activities of leaf stapling technique for assessing the response of RILs to SMD infestation
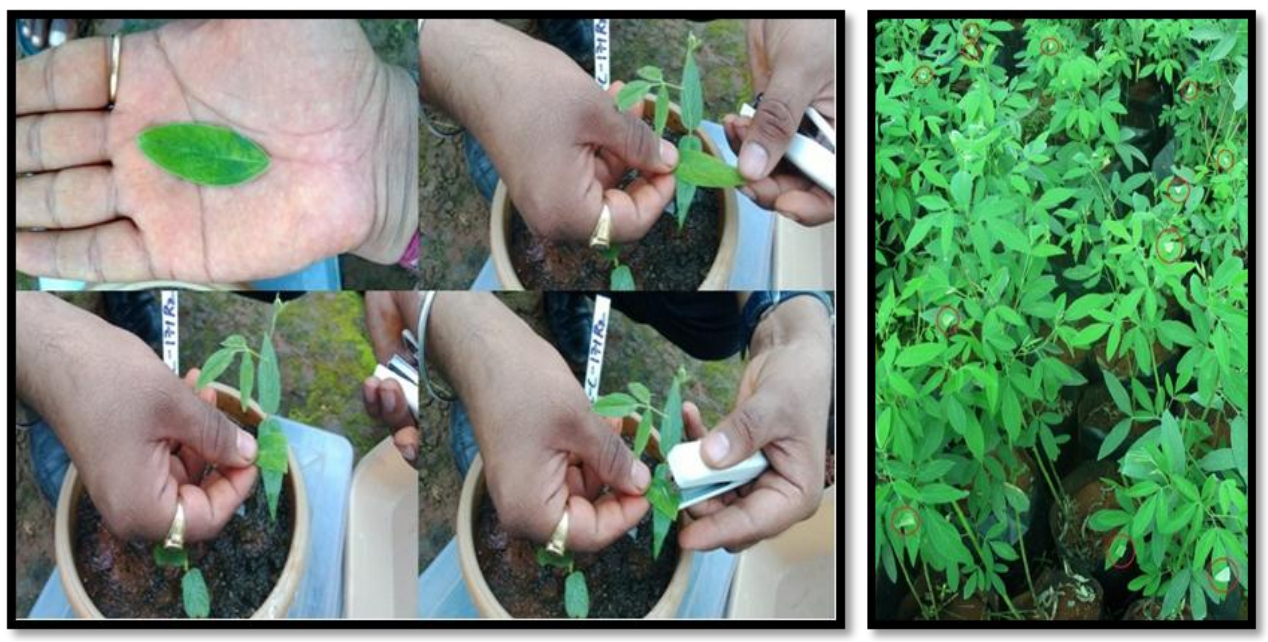

Fig.1 Frequency distribution graph of SMD incidence among 188 RIL population

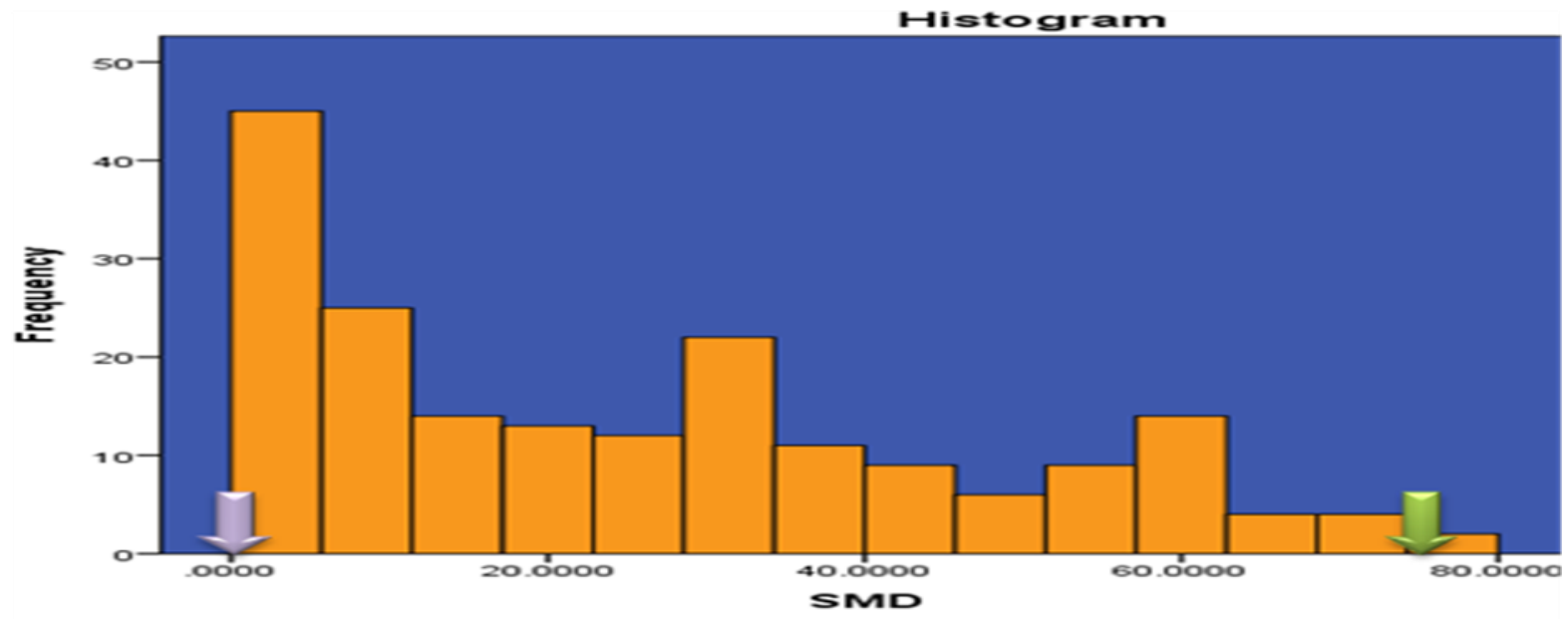

Fig.2 Schematic representation of segregation behavior of SV1 and SV2 genes in the cross ICPL $20097 \times$ ICP 8863

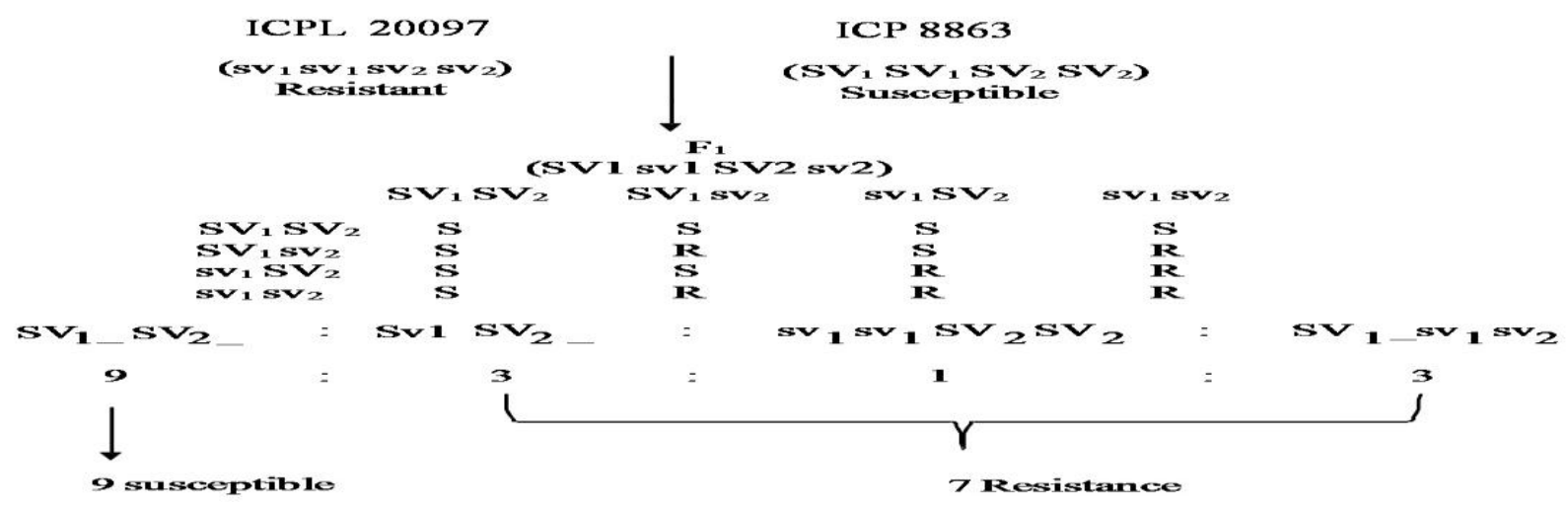


For obtaining resistant RILs, any one of the SMD locus or both the locus in homozygous recessive condition was required. Resistance was obtained whenever one or two or both the loci occur in homozygous recessive state $\left(\mathrm{sv}_{1}\right.$

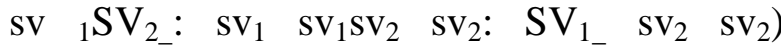
whereas dominant alleles at both loci $\left(\mathrm{SV}_{1}\right.$ $\mathrm{SV}_{2 \_}$) lead to susceptibility (Fig. 2).

There are diverse reports about the genetics of resistance to sterility mosaic disease depending on the scale, source of resistance and number of resistant genes present in the parents involved in the cross during investigation. Saxena (2008) proposed that, genetics of PSMD depend on the resistance source, PSMV isolates and scoring methods and hence the resistance to PSMD in pigeonpea appears to be complex. However, most of the studies have been reported as susceptibility is dominant and resistance to be under the control of recessive genes (Gnanesh et al., 2011 and Ganapathy et al., 2012). These different inheritance patterns could be attributed to the difference in parents used for developing segregation population (Srinivas et al., 1997 and Ganapathy et al., 2012) and different isolates used for screening (Srinivas et al., 1997). ICP 8863 is considered as indeterminate, mid-late and susceptible genotype to PPSMV (Gnanesh et al., 2011b and Saxena et al., 2010). Several researchers (Anjaneya Reddy et al., 2005., Kumar et al., 2005., Rangaswamy et al., 1997, Saifulla et al., 2005b., Saifulla et al., 2006., Gangawar and Bajpai, 2008 and Shiv Om et al., 2008) have also reported identification of SMD resistant genotypes from different kinds of mapping populations in pigeonpea. In the present study, 188 RILs showed digenic ratio (9S:7R) for SMD resistance, indicating complementary gene action which showed dominance of susceptibility over resistant and based on the per cent disease incidence, the RILs could be broadly classified as resistant (PDI <20\%) and susceptible (PDI > 20\%). The
SMD incidence among the 188 RILs ranged from 0 to $100 \%$ whereas, the susceptible parent (ICP 8863) showed mean value of $79.17 \%$ and resistant parent (ICPL 20097) showed it as $0 \%$. Out of total 188 RILs screened, 90 RILs showed resistant reaction to SMD infection while 98 RILs were susceptible.

\section{Acknowledgments}

Authors acknowledge Dr Rajeev K. Varshney and Dr Rachit Saxena from ICRISATHyderabad for providing seed material as 188 RIL population along with their parents i.e. ICPL 20097 and ICP 8863 and Dr Mamta Sharma for providing susceptible leaf material from the SMD infected plot.

\section{References}

Anjaneya Reddy, B., Muhammad Saifulla and Byre Gowda, M. 2005. Evaluation of genotypes for combined resistance to wilt and sterility mosaic of pigeonpea. Karnataka J. Agric. Sci., 18 (3):836838.

Ganapathy, K.N.M., Gowda, B., Ajay, B.C., Venkatesha, S.C., Gnanesh, B.N., Gomashe, S.S., Babu, P., Girish, G., Prasad, P. S., Veerakumar, G. N and Patil, J.V. 2012. Inheritance studies of sterility mosaic disease (SMD) resistance in vegetable type pigeonpea (Cajanus cajan (L.) Millsp.). AJCS. 6(7):1154-1158.

Gangwar, L.K., and Bajpai, G.C. 2008. Screening of interspecific hybrids against sterility mosaic disease in pigeonpea. Legume Res., 31(4): 306307.

Gnanesh, B. N., Bohra, A and Sharma, M. 2011. Genetic mapping and quantitative trait locus analysis of resistance to sterility mosaic disease in pigeonpea [Cajanus cajan (L.) Millsp.]. Field 
Crop Res, 123, 53-61.

Kumar, P.L., Latha, T.K. S., Kulkarni, N. K., Raghavendra, N., Saxena,K. B., Waliyar, F., Rangaswamy, K.T., Muniyappa, V., Sabitha Doraiswamy and Teifion, A. 2005, Broad based resistance to pigeonpea sterility mosaic disease in wild relatives of pigeonpea(Cajanus: Phaseoleae), Ann. Appl. Biol., 146: 371 - 379.

Rangaswamy, K.T., Sulladmath, V.V and Byregowda, M. 1997. Reaction of certain pigeonpea entries and varieties to sterility mosaic disease. Abs. Symposium on Economically Important Diseases of Crop Plants, IPS Southern chapter, University of Agricultural Sciences, Bangalore, Dec. 18-20, pp. 74.

Saifulla, M., Mahesh, M and Byre Gowda, M. 2006, Reaction of pigeonpea genotypes for sterility mosaic disease. In: Nat. Semin. On new frontiers in plant pathology. pp43, September 28-30, Shimoga, India.

Saifulla, M., Mahesh, M., Nagesha, G. K and Byre Gowda, M. 2005b, Management of sterility mosaic disease through host resistance in pigeonpea. In: Indian society of plant pathologists and centenary symposium on plant pathology.p36, April, 7- 8, Shimla. India.

Saxena, K.B., 2008. Genetic Improvement of Pigeonpea - a Review. Trop. Plant. Biol., 1:159-178.

Saxena, R.K., Saxena, K.B., Kumar, R.V., Hoisington, D.A and Varshney, R. K. 2010. Simple sequence repeat-based diversity in elite pigeonpea genotypes for developing mapping populations to map resistance to Fusarium wilt and sterility mosaic disease. Plant Breed, 129, 135-141.

Shiv Om Chauhan, V.B., Sarode, S.B and Wayazade, P.M. 2008, Screening of pigeonpea genotypes through different screening techniques against sterility mosaic disease. Asian J. Bio. Sci., 3(1): 5-10.

Singh, A.P., Singh, U. P., Singh, R. M and Rajni Raina, 2003. Relative efficiencies of four population improvement schemes in pigeonpea [Cajanus cajan (L.) Millsp.]. Crop Res., 25(2): 305311.

Srinivas, T., Reddy, M.V., Jain, K.C and Reddy, M.S.S. 1997. Inheritance of resistance to two isolates of sterility mosaic pathogen in Pigeonpea (Cajanus cajan (L.) Millsp.). Euphytica, 97: 4552.

\section{How to cite this article:}

Shourabh Joshi, T. Revathi, G. Umadevi, C.V. Sameer Kumar and Anuradha, G. 2017. Study of Sterility Mosaic Disease Resistance on Immortal Population in Pigeonpea. Int.J.Curr.Microbiol.App.Sci. 6(9): 697-702. doi: https://doi.org/10.20546/ijcmas.2017.609.085 